\title{
Review \\ Clinical review: Liberation from mechanical ventilation
}

Mohamad F El-Khatib and Pierre Bou-Khalil

Departments of Anesthesiology and Medicine, School of Medicine, American University of Beirut, Beirut 1107 2020, Lebanon

Corresponding author: Pierre Bou-Khalil, pb05@aub.edu.lb

Published: 6 August 2008

This article is online at http://ccforum.com/content/12/4/221

(c) 2008 BioMed Central Ltd
Critical Care 2008, 12:221 (doi:10.1186/cc6959)

predict patient tolerance of a 1 -hour period on minimal pressure support. Also, Afessa and colleagues [10] reported that critical care practitioners could not accurately forecast 3-day and 7-day weaning outcome for mechanically ventilated patients in a medical intensive care unit (ICU). Thus, there is a sound rationale that predicting readiness of patients to be successfully liberated from mechanical ventilation needs to be based on objective weaning predictors that can be applied in clinical decision making.

A large spectrum of weaning predictors has been studied, which can be divided into simple weaning indices, simple measures of load and capacity, integrative weaning indices, and complex predictors requiring special equipment. A recent expert panel [11] sponsored by the American College of Chest Physicians, Society of Critical Care Medicine, and the American Association for Respiratory Care developed evidence-based weaning guidelines and noted that only eight variables had some predictive capacity: minute ventilation $\left(V_{E}\right)$, negative inspiratory force, maximum inspiratory pressure, tidal volume $\left(V_{T}\right)$, breathing frequency $(f)$, the ratio of breathing frequency to tidal volume $\left(f / V_{T}\right), P_{0.1} / P_{\text {Imax }}$ (ratio of airway occlusion pressure $0.1 \mathrm{~s}$ after the onset of inspiratory effort to maximal inspiratory pressure), and CROP (integrative index of compliance, rate, oxygenation, and pressure) (Table 2). However, another recent study by Conti and colleagues [12] in 2004 showed that vital capacity, $V_{T}, P_{0.1}, V_{E}, f$, maximum inspiratory pressure, $f / V_{T}, P_{0.1} / P_{\operatorname{Imax}}$ and $P_{0.1} \times f / V_{T}$ are poor predictors of weaning outcome in a general ICU population. These conflicting results have been attributed to many factors, such as the measurement techniques that differ from one study to another, different timing of measurements made by different investigators, and lack of objective criteria to determine tolerance of the trial [13-16].

$\mathrm{ATC}=$ automatic tube compensation; $\mathrm{COPD}=$ chronic obstructive pulmonary disease; $\mathrm{CPAP}=$ continuous positive airway pressure; $\mathrm{CROP}=$ integrative index of compliance, rate, oxygenation, and pressure; $f=$ breathing frequency; $f / V_{T}=$ ratio of breathing frequency to tidal volume; ICU $=$ intensive care unit; NAVA $=$ neurally adjusted ventilation assist; NPPV $=$ non-invasive positive pressure ventilation; $P_{0.1} / P_{\operatorname{lmax}}=$ ratio of airway occlusion pressure $0.1 \mathrm{~s}$ after the onset of inspiratory effort to maximal inspiratory pressure; PAV = proportional assist ventilation; PEEP = positive end expiratory pressure; $\mathrm{PSV}=$ pressure support ventilation; $\mathrm{RSBI}=$ rapid shallow breathing index; $\mathrm{SIMV}=$ synchronized intermittent mandatory ventilation; $\mathrm{V}_{\mathrm{E}}=$ minute ventilation; $\mathrm{V}_{\mathrm{T}}=$ tidal volume. 
Table 1

\section{Variables that suggest readiness for spontaneous breathing trials}

Resolution of acute phase of disease

Intact airway reflexes

Cardiovascular stability (no need for continuous vasopressors)

Afebrile

$\mathrm{P}_{\mathrm{a}} \mathrm{O}_{2} / \mathrm{F}_{\mathrm{i}} \mathrm{O}_{2} \geq 150 \mathrm{mmHg}$

PEEP $\leq 5 \mathrm{cmH}_{2} \mathrm{O}$

$\mathrm{F}_{\mathrm{i}} \mathrm{O}_{2}$, fraction of inspired oxygen; $\mathrm{P}_{\mathrm{a}} \mathrm{O}_{2}$, partial pressure of arterial oxygen; PEEP, positive end expiratory pressure.

\section{Minute ventilation}

In 1973, Sahn and Lakshminarayan [17] reported that a $V_{E}$ $<10 \mathrm{l} /$ minute is associated with weaning success. Subsequent studies showed that $V_{E}$ values $>15-20 \mathrm{l} /$ minute are helpful in identifying patients who are unlikely to be liberated from mechanical ventilation but lower values were not helpful in predicting successful liberation [18-20]. More recently, Martinez and colleagues [21] showed that the time of recovery of $V_{E}$ from the end of a 2-hour spontaneous breathing trial to return to baseline after reinstitution of mechanical ventilation is a good predictor of liberation from mechanical ventilation. They concluded that short $V_{E}$ recovery times (3-4 minutes) may help in determining respiratory reserve and be valuable in predicting the success of extubation [21].

\section{Maximal inspiratory pressure}

$P_{\text {Imax }}$ (also called negative inspiratory force) is commonly used to test respiratory muscle strength and, in particular, the diaphragm. Trwit and Marini [22] described a method for measuring $P_{\text {Imax }}$ that is not dependent on patient cooperation. The proximal end of the endotracheal tube is occluded for 20 to 25 seconds with a one-way valve that allows the patient to exhale but not to inhale. This procedure leads to increasing inspiratory effort and $\mathrm{P}_{\text {Imax }}$ is measured towards the end of the occlusion period.

Several early studies [18-20] have shown that $\mathrm{P}_{\operatorname{lmax}} \leq-20$ to $-30 \mathrm{cmH}_{2} \mathrm{O}$ has a high sensitivity (ranging from $86 \%$ to $100 \%$ ) and low specificity (ranging from $7 \%$ to $69 \%$ ) for predicting liberation outcome from mechanical ventilation. These findings were further confirmed by Bruton [23], who reported that $\mathrm{P}_{\text {Imax }} \leq-17 \mathrm{cmH}_{2} \mathrm{O}$ has a sensitivity of $100 \%$ and a specificity of $50 \%$ for predicting extubation outcome. Thus, because of the confirmed low specificity, $P_{\text {Imax }}$ is not enough by itself to predict reliably the outcome of weaning, particularly in patients who exhibit a $\mathrm{P}_{\operatorname{lmax}} \geq-20$ to $-30 \mathrm{cmH}_{2} \mathrm{O}$.

\section{Tidal volume}

Spontaneous tidal volumes greater than $5 \mathrm{ml} / \mathrm{kg}$ have been considered as good predictors of weaning outcome [24,25]. More recent studies have used both qualitative and
Table 2

\begin{tabular}{lc}
$\begin{array}{l}\text { Indices used to predict success for weaning and ventilator } \\
\text { discontinuation }\end{array}$ & Threshold values \\
\hline Index & $<10 \mathrm{l} /$ minute \\
\hline $\begin{array}{l}\text { Ventilatory drive } \\
\quad \text { Minute ventilation }\left(\mathrm{V}_{\mathrm{E}}\right)\end{array}$ & $<0.3$ \\
$\mathrm{P}_{0.1} / \mathrm{P}_{\text {Imax }}$ & \\
Respiratory muscle strength & $<-20$ to $-30 \mathrm{cmH}_{2} \mathrm{O}$ \\
$\quad \begin{array}{l}\text { Maximum inspiratory pressure }\left(\mathrm{P}_{\mathrm{Imax}}\right) \\
\text { Ventilatory mechanics }\end{array}$ & $>5 \mathrm{ml} / \mathrm{kg}$ \\
$\quad \begin{array}{l}\text { Tidal volume }\left(\mathrm{V}_{\mathrm{T}}\right) \\
\text { Breathing frequency }(\mathrm{f})\end{array}$ & $<30-35 \mathrm{breaths} / \mathrm{minute}$ \\
$\quad$ Rapid shallow breathing $\left(\mathrm{f} / \mathrm{V}_{\mathrm{T}}\right)$ & $<105 \mathrm{breaths} / \mathrm{minute} / \mathrm{ml}$ \\
Others & \\
Integrative index $(\mathrm{CROP})$ & $>13 \mathrm{ml} / \mathrm{breaths} /$ minute
\end{tabular}

$\mathrm{P}_{0.1} / \mathrm{P}_{\mathrm{Imax}}=$ ratio of airway occlusion pressure $0.1 \mathrm{~s}$ after the onset of inspiratory effort to $P_{\text {Imax }}$.

quantitative non-linear dynamical analysis of the tidal volume pattern for discriminating between outcome success and failure from mechanical ventilation [26,27]. Engoren [26] and El-Khatib and colleagues [27] showed that approximate entropy of the tidal volume and breathing frequency patterns, a technique that measures the amount of regularity in a series, is a useful indicator of reversibility of respiratory failure. They reported that low approximate entropy that reflects regular tidal volume and respiratory frequency patterns is a good indicator of weaning success.

\section{Breathing frequency}

Tachypnea ( $\mathrm{f} \geq 30$-35 breaths/minute) is a sensitive marker of respiratory distress but can prolong intubation when used as an exclusive criterion $[18,25,28,29]$. El-Khatib and colleagues [27] have shown that it is the degree of regularity/irregularity in the pattern of the breathing frequency as reflected by approximate entropy rather than the absolute value of the breathing frequency that is important in discriminating between weaning success and failure. They have shown that a highly irregular spontaneous breathing frequency pattern with or without periods of apneas is not a good indicator for liberation from mechanical ventilation outcome [27].

\section{The ratio of breathing frequency to tidal volume}

Tobin and colleagues [30] first noted that patients who failed to liberate from mechanical ventilation developed significantly more rapid (32 versus 21 breaths/minute) and shallow (194 versus $398 \mathrm{ml} / \mathrm{breath}$ ) breathing than those who succeeded. Yang and Tobin [18] then performed a prospective study of 100 medical patients receiving mechanical ventilation in the ICU in which they demonstrated that the ratio of frequency to tidal volume (rapid shallow breathing index (RSBI)) obtained during the first 1 minute of a T-piece trial and at a threshold 
value of $\leq 105 \mathrm{breaths} /$ minute/l was a significantly better predictor of weaning outcomes than other 'classic' and commonly used parameters. Since then, the RSBI has been studied in large numbers of patients and appears to have predictive utility that is superior to other commonly used parameters [31-34]. However, there remains a principle shortcoming in the RSBI: it can produce excessive false positive predictions (that is, patients fail weaning outcome even when RSBI is $\leq 105$ breaths/minute/l) [35-36]. Also, the $\mathrm{RSBI}$ has less predictive power in the care of patients who need ventilatory support for more than 8 days and may be less useful in chronic obstructive pulmonary disease (COPD) and elderly patients [37-39]. In a non-homogenous group of patients including COPD patients, Tanios and colleagues [40] reported that including the $\mathrm{RSBI}$ in a protocol can prolong weaning time from 2 days to 3 days. Nevertheless, an $\mathrm{RSBI}$ of $\leq 105$ breaths/minute/l should prompt a spontaneous breathing trial of 30 to 120 minutes to further assess patient readiness for liberation from mechanical ventilation.

The RSBI threshold can be influenced by the ventilatory support settings, the experimental conditions, and the patient population. The ratio must be calculated as per Yang and Tobin [18], otherwise different threshold values for the index might be needed $[9,15,38,41]$. When measured during trials of pressure support ventilation, the RSBI was of limited value in predicting weaning outcome [9]. El-Khatib and colleagues $[15,16]$ showed that the ventilatory support settings can have a significant influence on the RSBI values in the same patient population. They showed that the RSBI significantly decreased during a trial of pressure support ventilation, during a continuous positive airway pressure (CPAP) trial on $40 \%$ oxygen, and during a CPAP trial on room air as compared to a trial of 1 minute spontaneously breathing room air and off the ventilator. They recommended that the predictive value of the RSBI reported by Yang and Tobin should only be adopted if the determination of the index is performed under similar experimental conditions to those applied by Yang and Tobin, where patients were disconnected from the ventilator and spontaneously breathed room air for 1 minute. Furthermore, El-Khatib and colleagues $[15,16]$ recommended that different threshold values for the RSBI should be derived for different ventilatory support levels. Krieger and colleagues [38] showed that when adjusting the threshold value of the RSBI to $\leq 130$ breaths/minute/l, the RSBI measured at 3 hours was very effective in predicting weaning success among patients 70 years and older. These studies support the fact that the RSBI may be one of the better indexes for predicting weaning outcome that can easily be applied at the bedside, and can be readily utilized to identify patients who are candidates for spontaneous breathing trial.

\section{$\mathbf{P}_{0.1} / \mathbf{P}_{\text {Imax }}$}

The airway occlusion pressure $\left(P_{0.1}\right)$ is the pressure measured at the airway opening $0.1 \mathrm{~s}$ after inspiring against an occluded airway [42]. The $P_{0.1}$ is effort independent and correlates well with central respiratory drive. When combined with $\mathrm{P}_{\text {Imax }}$, the $\mathrm{P}_{0.1} / \mathrm{P}_{\text {Imax }}$ ratio at a value of $<0.3$ has been found to be a good early predictor of weaning success $[11,43]$ and may be more useful than either $P_{0.1}$ or $P_{I \max }$ alone. Previously, the clinical use of $\mathrm{P}_{0.1} / \mathrm{P}_{\operatorname{Imax}}$ has been limited by the requirement of special instrumentation at the bedside; however, new and modern ventilators are incorporating respiratory mechanics modules that provide numerical and graphical displays of $\mathrm{P}_{0.1}$ and $\mathrm{P}_{\operatorname{Imax}}$.

\section{CROP}

The CROP index is an integrative index that incorporates several measures of readiness for liberation from mechanical ventilation, such as dynamic respiratory system compliance $\left(\mathrm{C}_{\mathrm{rs}}\right)$, spontaneous breathing frequency $(\mathrm{f})$, arterial to alveolar oxygenation (partial pressure of arterial oxygen $\left(\mathrm{P}_{\mathrm{a}} \mathrm{O}_{2}\right)$ /partial pressure of alveolar oxygen $\left(\mathrm{P}_{\mathrm{A}} \mathrm{O}_{2}\right)$ ), and $\mathrm{P}_{\text {Imax }}$ in the following relationship:

$$
\mathrm{CROP}=\left[\mathrm{C}_{\mathrm{rs}} \times \mathrm{P}_{\operatorname{Imax}} \times\left(\mathrm{P}_{\mathrm{a}} \mathrm{O}_{2} / \mathrm{P}_{\mathrm{A}} \mathrm{O}_{2}\right)\right] / \mathrm{f}
$$

where:

$$
\mathrm{P}_{\mathrm{A}} \mathrm{O}_{2}=\left(\mathrm{P}_{\mathrm{B}}-47\right) \times \mathrm{F}_{\mathrm{i}} \mathrm{O}_{2}-\mathrm{P}_{\mathrm{a}} \mathrm{CO}_{2} / 0.85
$$

and $P_{B}$ is barometric pressure.

The CROP index assesses the relationship between the demands placed on the respiratory system and the ability of the respiratory muscles to handle them [18]. Yang and Tobin [18] reported that a CROP value $>13 \mathrm{ml} /$ breaths/minute offers a reasonably accurate predictor of weaning mechanical ventilation outcome. In 81 COPD patients, Alvisi and colleagues [39] showed that a CROP index at a threshold value of $>16 \mathrm{ml} /$ breaths $/$ minute is a good predictor of weaning outcome. However, one disadvantage of the CROP index is that it is somewhat cumbersome to use in the clinical setting as it requires measurements of many variables with the potential risk of errors in the measurement techniques or the measuring device, which can significantly affect the value of the CROP index.

\section{Testing for readiness of liberation from mechanical ventilation}

The ultimate goal of mechanical ventilatory support is liberation from the ventilator. In the majority of patients this is a simple process. A quick and direct method of testing readiness for liberation from mechanical ventilation is simply to initiate a trial of unassisted spontaneous breathing in the form of either a T-piece trial, a CPAP trial, or a pressure supported ventilation (PSV) trial. The decision on which trial to use remains largely a matter of physician preference; however, an important underlying rule is 'DO NOT EXHAUST' [44].

The classical approach for readiness testing is the spontaneous breathing trial with either a T-piece or a CPAP 
trial [45]. T-piece or CPAP trials can be used for two objectives: to test readiness for liberation from mechanical ventilation; or to implement a weaning protocol that involves increasing periods of unsupported spontaneous breathing interspersed with periods of full ventilatory support [46]. Wysocki and colleagues [46] showed that the reduced breathing variability in the breathing pattern was a marker of poor outcome from mechanical ventilation. This is in contrast to previous findings by Engoren [26] and El-Khatib and colleagues [27]. However, these discrepancies can be explained by the differences in the experimental set-ups as Engoren and El-Khatib and colleagues were assessing variability in breathing pattern during minimal ventilatory support while Wysocki and colleagues were assessing breathing pattern during a T-piece trial and when patients were off any ventilatory support. A subject of considerable interest is the duration of the T-piece or CPAP trials that best reflect patient readiness for liberation from mechanical ventilation. Large randomized controlled trials indicate that the mean time for a T-piece trial failure is approximately 40 to 50 minutes $[2,3,6]$. The proper trial duration for those conducted on CPAP or PSV is not well known. However, there is convincing evidence $[2,3,6,47]$ that a spontaneous breathing trial with either T-piece, CPAP, or PSV should be conducted for 30 to 120 minutes in order to test readiness for liberation from mechanical ventilation. It is likely that patients requiring more prolonged mechanical ventilation will require longer spontaneous breathing trials [48].

One advantage of using PSV instead of a T-piece or CPAP trials is its capacity to overcome the work of breathing imposed by the ventilator and the endotracheal tube $[49,50]$, particularly after a significant stay on mechanical ventilation during which it is anticipated that the tube radius is narrow or there are secretions lining the endotracheal tube lumen [51,52]. One major issue remains the level of pressure support required to overcome the imposed work of breathing while avoiding either over-assisting, which can result in excessive numbers of extubation failures, or under-assisting, which can result in unnecessarily prolonged mechanical ventilation. Studies have shown that the appropriate PSV level differs substantially from patient to patient $[49,50]$. Some studies have recommended the use of 5 to $7 \mathrm{cmH}_{2} \mathrm{O}$ of pressure support to offset the imposed work of breathing imposed by the breathing circuit, ventilator, and endotracheal tube resistances $[2,4]$.

Esteban and colleagues [3] showed in patients who failed a first spontaneous breathing trial that the median duration of weaning was 5 days for synchronized intermittent mandatory ventilation (SIMV), 4 days for PSV, and 3 days for T-piece trials. Other investigations indicated that the degree of respiratory muscle rest on SIMV is not proportional to the level of ventilatory support [53,54]. Combining PSV and SIMV reduced the pressure-time product and the work of breathing of the intervening and mandatory breaths, compared to SIMV alone [55]. Nevertheless, there is strong evidence that in patients who fail their initial attempt at spontaneous breathing (Table 3), SIMV weaning is inferior to repetitive and scheduled $\mathrm{T}$-piece trials or PSV trials and serves to prolong the duration of mechanical ventilation $[2,3]$.

Alongside T-piece, CPAP, and PSV trials, other modern forms of assisted spontaneous breathing (automatic tube compensation (ATC), proportional assist ventilation (PAV) and neurally adjusted ventilation assist (NAVA)) have been developed and brought to technical fruition in recent years. While PSV provides a constant pressure support level that can lead to either under-compensation and/or over-compensation of the pressure drop across the endotracheal tube, ATC provides a programmable pressure that is intended to compensate for the endotracheal tube resistance during inspiration and expiration according to the actual gas flow [56]. As such, ATC compensates continuously for the endotracheal tube and, hence, is sometimes referred to as electronic extubation [57]. Kuhlen and colleagues [56] showed that in weaning from mechanical ventilation, patients' work of breathing during spontaneous breathing trials is reduced by the application of PSV of $7 \mathrm{cmH}_{2} \mathrm{O}$ whereas the workload during automatic tube compensation corresponded to the values during trials of spontaneous breathing through a T-piece. Cohen and colleagues [57] showed that significantly more patients undergoing a spontaneous breathing trial with ATC were able to maintain spontaneous breathing for 48 hours after discontinuation of mechanical ventilation and extubation than with CPAP alone. Although not much research has been done on PAV and NAVA as newer weaning modes, some researchers have postulated a potential role of PAV and NAVA in weaning patients from mechanical ventilation $[58,59]$. Much research is needed in this area.

\section{Etiology of liberation failure}

When a patient fails a spontaneous breathing trial (Table 3), this should prompt the clinicians to conduct a systematic search for the reversible factors that may be responsible for weaning failure. Some of these factors may be simple to correct while others may be impossible to correct.

\section{Respiratory factors}

The vast majority of patients who fail a spontaneous breathing trial do so because of an imbalance between respiratory muscle capacity and the load placed on the respiratory system $[30,60]$. High airway resistance (bronchospasm and excessive airway secretions) [61-63] and low respiratory system compliance (stiff chest wall, stiff lungs, flooded or atelectatic alveoli) $[64,65]$ contribute to the increased work of breathing necessary to breathe and can lead to unsuccessful liberation from mechanical ventilation.

The presence of auto-positive end expiratory pressure (autoPEEP), commonly observed in COPD patients, can increase 
Table 3

\section{Criteria for failure of spontaneous breathing trial}

Anxiety

Diaphoresis

Greater than 20 to 25 percent increase in heart rate and/or blood pressure

Increased use of accessory muscles and dyspnea

Respiratory rate $>35$ breaths/minute

$\mathrm{S}_{\mathrm{p}} \mathrm{O}_{2}<90$ percent or greater than 5 percent decrease from baseline

$\mathrm{S}_{\mathrm{p}} \mathrm{O}_{2}$, oxygen saturation.

the pressure gradient needed to inspire, whether triggering the ventilator or spontaneous breathing $[66,67]$. This inspiratory threshold raises the work of breathing and leads to failure of liberation from mechanical ventilation [68]. When a spontaneous breathing trial signals a strength-load imbalance, the trial should be terminated so as to avoid respiratory muscle exhaustion and subsequent hypercapnia and hypoxemia.

\section{Major organ system failure}

Myocardial dysfunction can cause liberation from mechanical ventilation intolerance [69-71]. Myocardial ischemia is another mechanism causing failure of cardiac-induced liberation from mechanical ventilation [72,73]. Frazier and colleagues [72] recommended that clinicians must be aware of the potential for silent myocardial ischemia, monitor and evaluate their patients for such, and intervene to promote optimal cardiovascular function, particularly during the stress of liberation from mechanical ventilation. Vieira and colleagues [74] investigated whether the occurrence of acute kidney injury has any effect on liberation from mechanical ventilation. They reported that renal dysfunction has serious consequences for the duration of mechanical ventilation, liberation from mechanical ventilation, and mortality in critically ill patients [74]. Thyroid gland dysfunction has also been associated with decreased liberation from mechanical ventilation success [75]. Huang and Lin [76] evaluated whether stress dose corticosteroid supplementation can improve ventilator weaning in patients with adrenal insufficiency. They reported that early identification of adrenal insufficiency and appropriate supplementation with stress dose hydrocortisone increase the success of ventilator weaning and shorten the weaning period. Critical illness polyneuropathy has been reported to cause prolonged duration of mechanical ventilation [77,78]. GarnachoMontero and colleagues [78] reported in a cohort of 64 patients that weaning failure occurred in $79 \%$ of the patients with critical illness polyneuropathy versus $20 \%$ of patients without critical illness polyneuropathy.

\section{Nutritional status and electrolyte balance}

Nutrition should be assessed to ensure that it is adequate to maintain respiratory muscle mass and force [79]. Optimal nutritional support frequently improves liberation from mechanical ventilation, particularly when overfeeding is avoided. Excessive carbohydrate feeding can increase carbon dioxide production and may precipitate acute hypercapnic respiratory failure $[79,80]$.

\section{Psychological factors}

Psychological factors may be among the important nonrespiratory factors contributing to unsuccessful liberation from mechanical ventilation and leading to ventilator dependence [11,81-84]. Anxiety, fear, and stress manifested as rapid shallow breathing, tachycardia, and hypertension should be minimized [81]. Frequent communication among the ICU health care team, patient, and patient's family can be helpful in reducing/eliminating psychological factors. The process of liberation from mechanical ventilation should be explained to patients and reassurance for patients during the spontaneous breathing trials should be provided [82]. Sedatives should be used cautiously because they can depress the respiratory drive. Girard and colleagues [85] showed that a paired sedation and ventilator weaning protocol consisting of daily spontaneous awakening trials plus spontaneous breathing trials resulted in patients spending more time off mechanical ventilation, less time in coma, and less time in intensive care and the hospital.

\section{Technical factors}

When the ventilator is not adjusted appropriately, it can impose exhausting respiratory muscle workload during spontaneous breathing trials with either CPAP or PSV. The inspiratory valve triggering sensitivity when set inappropriately can increase the work of breathing needed to trigger the ventilator. Flow triggering ( 1 to $2 \mathrm{l} /$ minute) has been shown to be more effective and to result in lower workload of breathing to trigger the ventilator than pressure triggering during liberation from mechanical ventilation $[86,87]$. Also, the endotracheal tube can contribute to weaning failure. Endotracheal tube resistance increases over time as the tube becomes encrusted with secretions and its cross-sectional area reduced. During a T-piece trial, endotracheal tubes with high resistance can impose a significant workload on the patient's respiratory muscles, which can contribute to weaning failure $[50,56,88]$.

During his examination of protocols for hastening liberation of patients from mechanical ventilation, Ely [89] presented the jargon "WHEANS NOT", which summarizes that patients with present wheezes, heart disease, electrolytes imbalance, anxiety, neuromuscular disease, sepsis, nutrition insufficiency, receiving opiates, and with thyroid disease remain at risk for failure of liberation from mechanical ventilation and should prompt clinicians to address these issues.

\section{Value of weaning protocols}

There is very strong evidence that weaning/liberation protocols can be successfully implemented in ICUs while 
expediting weaning and improving the success of liberation from mechanical ventilation [90-94]. These protocols, whether they are physician-directed or implemented by respiratory therapists and ICU nurses, can enhance clinical outcomes and reduce costs of caring for critically ill patients. Marelich and colleagues [95] evaluated the effect of a single ventilator weaning protocol used in medical and surgical ICUs on the duration of mechanical ventilation and the incidence of ventilator associated pneumonia. They reported that a multidisciplinary weaning protocol was effective in reducing the duration of mechanical ventilatory support (from a median of 124 hours to a median of 68 hours) without any adverse effects on patient outcome. Also, they indicated that the weaning protocol was associated with a $50 \%$ decrease in incidence of ventilator-associated pneumonia. Similarly, Dries and colleagues [96] showed that protocol-driven weaning reduces the use of mechanical ventilation from 0.47 to 0.33 ventilator days/ICU days and reduces by $71 \%$ the incidence of ventilator-associated pneumonia in surgical ICU patients. Using a handheld computer, Iregui and colleagues [97] showed that respiratory care practitioners employing a weaning protocol programmed on a handheld computer can wean patients from mechanical ventilation more efficiently compared with the use of a paper-based weaning protocol. Lellouche and colleagues [98] compared usual care for weaning with a computer-driven weaning protocol based on a feedback system that uses the ventilatory pattern and endtidal $\mathrm{CO}_{2}$ to drive the appropriate pressure support levels. They reported that weaning duration was reduced in the computer-driven group from a median of 5 to 3 days and the total duration of mechanical ventilation from 12 to 7.5 days. The computer-driven weaning protocol also decreased median ICU stay from 15.5 to 12 days [98]. In cardiac surgery patients, Petter and colleagues [99] showed that during adaptive support ventilation, a ventilatory mode providing automatic adjustments of the ventilator settings, the outcome of tracheal extubation was comparable to PSV, with fewer ventilator setting manipulations and a smaller number of alarms. They suggested that adaptive support ventilation may simplify postoperative ventilatory support without delaying extubation. Much research is needed to identify any role for the modern modes of assisted spontaneous breathing in expediting and improving liberation from mechanical ventilation.

Whereas many controlled trials conducted in North America have demonstrated the effectiveness of nursing-based and respiratory therapist-based protocols in the early liberation from mechanical ventilation and reducing the length of stay in the ICU [100-103], weaning from mechanical ventilation in Europe has generally been less common and mainly physician-directed. Blackwood and colleagues [104] interviewed a sample of ten consultant physicians in two European ICUs and reported that although local physicians were supportive in theory, introduction of protocolized weaning is likely to be difficult because of the breadth of information required for successful decision making.
Consultants' views in this study were not consistent with North American findings that physicians' caution may unnecessarily prolong weaning. Two recent European studies reported conflicting results on the utility of protocolized weaning in affecting the outcome and duration of mechanical ventilation. Blackwood and colleagues [105], using a physician-driven protocol, reported that protocolized weaning did not reduce the duration of mechanical ventilation and was not associated with an increased rate of re-intubation or ICU mortality, while Tonnelier and colleagues [106], using a nurses' protocolized-directed weaning strategy, showed a shorter duration of mechanical ventilation and a shorter length of stay in the ICU, with no difference in extubation failure or incidence of ventilator-associated pneumonia in patients requiring ventilatory support for greater than 48 hours. However, it should be pointed out that most (if not all) of the above clinical studies supporting these weaning approaches did not routinely use daily spontaneous breathing trials in the control group.

In 2006, Goodman [107] described how a weaning protocol is designed and introduced into the critical care unit of a district general hospital. He indicated that a multi-professional group interested in weaning needs to work to formulate a protocol, to implement the protocol into the ICU, and to maintain an ongoing auditing system.

While each institution must customize the weaning protocols to its local practice, there are important general concepts that may ease the process of implementation and enhance success [105]. First, protocols should not be viewed as static constructs, but rather dynamic tools in evolution, which can be modified to accommodate new data and/or clinical practice guidelines. Second, institutions must be prepared to commit the necessary resources (for example, technology and personnel) to develop and implement weaning protocols.

\section{Non-invasive ventilation}

Patients with limited ventilatory reserve or chronic pulmonary disease can benefit from non-invasive positive pressure ventilation (NPPV) in the period post-extubation and after liberation from mechanical ventilation. Ferrer and colleagues [108] showed that earlier extubation with NPPV resulted in shorter duration of mechanical ventilation and length of stay, less need for tracheostomy, and lower incidence of complications, and improved survival in 21 patients who had failed a weaning trial for 3 consecutive days. In patients with an exacerbation of COPD, Nava and colleagues [109] showed that NPPV facilitated extubation within 48 hours after intubation, decreasing the period of ventilatory support, the ICU stay, and the incidence of nosocomial pneumonia as well as increasing survival. A recent meta-analysis [110] of five studies and 171 patients reported that the use of NPPV facilitated weaning with a consistent positive effect of noninvasive weaning on mortality. However, caution should be exercised not to prolong non-beneficial use of NPPV, 


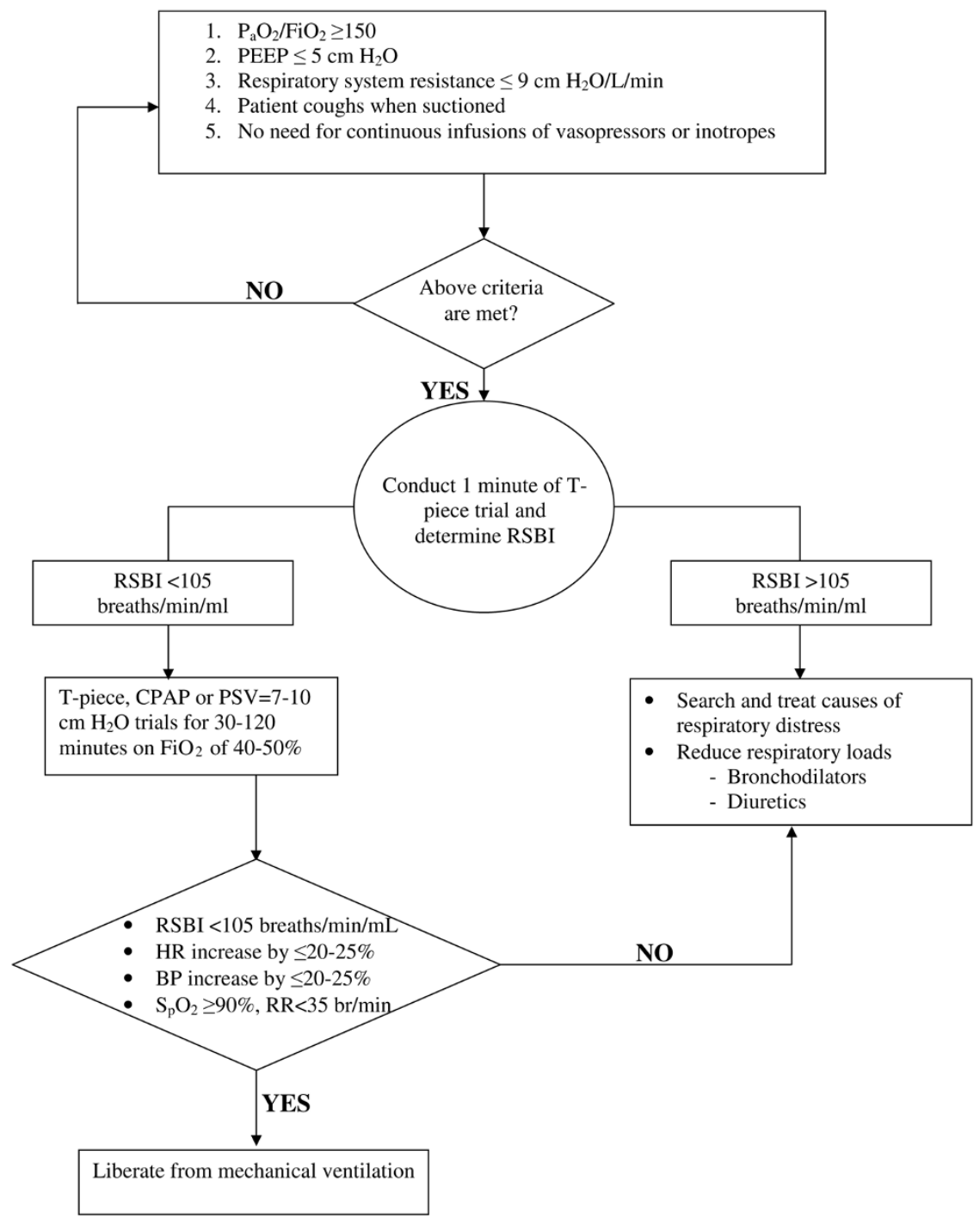

Algorithm for liberation from mechanical ventilation. BP, blood pressure; CPAP, continuous positive airway pressure; $\mathrm{F}_{\mathrm{i}} \mathrm{O}_{2}$, fraction of inspired oxygen; $\mathrm{HR}$, heart rate; $\mathrm{P}_{\mathrm{a}} \mathrm{O}_{2}$, partial pressure of arterial oxygen; PEEP, positive end expiratory pressure; PSV, pressure support ventilation; RR, respiration rate; $\mathrm{RSBI}$, rapid shallow breathing index; $\mathrm{S}_{\mathrm{p}} \mathrm{O}_{2}$, oxygen saturation.

particularly in non-COPD patients, as this may worsen outcomes [111]. In a group of 221 patients with similar baseline characteristics and who were randomly assigned to either NPPV (114 patients) or standard medical care (107 patients), Esteban and colleagues [111] showed that NPPV did not reduce mortality or the need for re-intubation among patients receiving mechanical ventilation who had respiratory failure after extubation. The mortality rate tended to be higher among the patients assigned to NPPV than among those assigned to standard medical therapy, suggesting that unnecessarily prolonged use of NPPV may worsen outcomes by delaying necessary re-intubation.

\section{Extubation}

Extubation (that is, removal of the endotracheal tube) is the second stage in the liberation from mechanical ventilation process. It should be considered and attempted after patients have passed a spontaneous breathing trial as part of the liberation process. However, even with the success of a spontaneous breathing trial, the possibility of an extubation failure (that is, the need for re-intubation within 48 to 72 hours) is $10 \%$ to $20 \%[112,113]$. Some of the factors that have been implicated in such extubation failures include cough strength, propensity for aspiration, volume of secretions and suctioning frequency, level of consciousness, 
and potential for upper airway stridor [114-116]. Decreasing the risk for extubation failure necessitates the thorough assessment of patients' ability to cough and clear airway secretions [114,115] as well as the use of steroids for patients who are at risk of post-extubation laryngeal edema [116].

\section{The role of tracheostomy in liberation from mechanical ventilation}

The role of tracheostomy in liberation from mechanical ventilation has been the subject of several studies. The benefits commonly ascribed to tracheostomy [117-121] include increased patient comfort, decreased airway resistance, better secretion removal, improved oral hygiene, less laryngeal damage, and ability to eat and speak. Boynton and colleagues [119] showed in an observational prospective cohort study that the median duration of weaning was 3 days in surgical patients who underwent tracheostomy prior to any active weaning attempts versus 6 days in patients in whom initial weaning attempts were made with the endotracheal tube in place. The frequency of fatigue and pneumonia were also lower in the patients who underwent early tracheostomy. Diehl and colleagues [120] and Davis and colleagues [121] reported that the work of breathing decreased by $26 \%$ to $55 \%$, the pressure-time index decreased by $55 \%$, the airway resistance decreased from 9.4 to $6.3 \mathrm{cmH}_{2} \mathrm{O} / \mathrm{l} / \mathrm{s}$, and the auto-PEEP decreased from 2.9 to $1.6 \mathrm{cmH}_{2} \mathrm{O}$ following tracheostomy. They postulated that the rigid nature of the tracheostomy tube represents reduced imposed work of breathing compared with the longer, thermoliable endotracheal tube and concluded that tracheostomy can substantially reduce the mechanical workload of ventilatordependent patients.

\section{An approach to liberation from mechanical ventilation}

Each institution should develop its own protocol for liberation from mechanical ventilation that is based on solid scientific data and take into consideration the level of personal and technical support in the ICU. The algorithm presented in Figure 1 reflects our institutional protocol for liberation from mechanical ventilation, which is not meant as a guideline but just an example of a simple bedside approach to the liberation from mechanical ventilation. An essential component of our evaluation for readiness for a spontaneous breathing trial involves the assessment of respiratory system resistance, particularly in patients who have received mechanical ventilation for more than 7 days. Measurement of the respiratory system resistance (which includes endotracheal tube resistance) is performed with an end-inspiratory occlusion maneuver [122] during mechanical ventilation and prior to initiation of the spontaneous breathing trial. This will particularly give us an insight into the endotracheal tube condition (that is, endotracheal tube resistance), which can be a major workload during the subsequent spontaneous breathing trial. For resistance values $\leq 9 \mathrm{cmH}_{2} \mathrm{O} / \mathrm{l} /$ minute, patients can receive a spontaneous breathing trial with a T-piece, otherwise patients will undergo spontaneous breathing trials with CPAP or PSV.

\section{Conclusion}

Successful liberation from mechanical ventilation in the ICU depends on the application of skilled judgment, decision making, and medical and nursing interventions. Most patients do not require a prolonged period of gradual withdrawal of mechanical ventilation, which carries the risks of ventilatorinduced lung injury, nosocomial pneumonia, airway trauma, and increased cost of care. On the other hand, overly aggressive and premature discontinuation of ventilatory support can precipitate ventilatory muscle fatigue, gasexchange failure, and loss of airway protection. The last two decades of research have provided the information necessary to make adequate clinical decisions in liberating patients from mechanical ventilation.

Key points with regard to liberation from mechanical ventilation are: most mechanically ventilated patients can be liberated from mechanical ventilation after a short spontaneous breathing trial; most weaning predictors may not be sufficiently accurate for liberation decision-making, although they are helpful in identifying causes of respiratory failure; the overall medical management of patients who continue to require ventilatory support should be continuously re-evaluated to ensure that all factors contributing to ventilator-dependence are assessed; ventilatory support strategies should be aimed at maximizing patient comfort and unloading of the respiratory muscles; the duration of spontaneous breathing trials can be anywhere from 30 to 120 minutes; and the duration of mechanical ventilation can be reduced by using clinical protocols that can be executed by respiratory therapists and ICU nurses and not necessarily by ICU physicians.

\section{Competing interests}

The authors declare that they have no competing interests.

\section{References}

1. Hall JB, Wood LDH: Liberation of the patient from mechanical ventilation. JAMA 1987, 257:1621-1628.

2. Brochard L, Rauss A, Benito S, Conti G, Mancebo J, Rekik N, Gasparetto A, Lemaire F: Comparison of three methods of gradual withdrawal from ventilatory support during weaning from mechanical ventilation. Am J Respir Crit Care Med 1994, 150:896-903.

3. Esteban A, Furtos F, Tobin MJ, Alia I, Solsona JF, Vallverdu I, Fernandez R, de la Cal MA, Benito S, Tomas R, Carriedo D, Macias $\mathrm{S}$, Blanco J: A comparison of four methods of weaning patients from mechanical ventilation. Spanish Lung Failure Collaborative Group. N Engl J Med 1995, 332:345-350.

4. Esteban A, Alia I, Gordo F, Fernandez R, Solsona JF, Vallverdu I, Macia S, Allegue JM, Blanco J, Carriedo D, Leon M, de la Cal MA, Taboada F, Gonzalez de Velasco J, Palazon E, Carizosa F, Tomas R, Suarez J, Goldwasser RS: Extubation outcome after spontaneous breathing trials with T-tube or pressure support ventilation. Spanish Lung Failure Collaborative Group. Am J Respir Crit Care Med 1997, 156:459-465.

5. Esteban A, Alia I, Tobin MJ, Gil A, Gordo F, Vallverdu I, Blanch L, Bonet A, Vazquez A, de Pablo R, Torres A, de la Cal MA, Macias $S$ : Effect of spontaneous breathing trial duration on outcome 
of attempts to discontinue mechanical ventilation. Spanish Lung Failure Collaborative Group. Am J Respir Crit Care Med 1999, 159:512-518.

6. Vallverdu I, Calaf N, Subirana M, Net A, Benitto S, Mancebo J: Clinical characteristics, respiratory functional parameters, and outcome of two-hour T-piece trial in patients weaning from mechanical ventilation. Am J Respir Crit Care Med 1998, 158: 1855-1862.

7. Esteban A, Alia I, Ibanez J, Benito S, Tobin MJ: Modes of mechanical ventilation and weaning: a national survey of Spanish hospitals. The Spanish Lung Failure Collaborative Group. Chest 1994, 106:1188-1193.

8. Nevins ML, Epstein SK: Predictors of outcome for patients with COPD requiring invasive mechanical ventilation. Chest 2001, 119:1840-1845.

9. Stroetz RW, Hubmayr RD: Tidal volume maintenance during weaning with pressure support. Am J Respir Crit Care Med 1995, 152:1034-1040.

10. Afessa B, Hogans L, Murphy R: Predicting 3-day and 7-day outcomes of weaning from mechanical ventilation. Chest 1999, 116:456-461.

11. Maclntyre NR, Cook DJ, Ely EW Jr, Epstein SK, Fink JB, Heffner JE, Hess D, Hubmayer RD, Scheinborn DJ: Evidence-based guidelines for weaning and discontinuing ventilatory support: a collective task force facilitated by the American College of Chest Physicians; the American Association for Respiratory Care; and the American College for Critical Care Medicine. Chest 2001, 120:375S-395S.

12. Conti G, Montini L, Pennisi MA, Cavaliere F, Arcangeli A, Bocci $M G$, Proietti $R$, Antonelli M: A prospective, blinded evaluation of indexes proposed to predict weaning from mechanical ventilation. Intensive Care Med 2004, 30:830-836.

13. Epstein SK: Weaning parameters. Respir Care Clin N Am 2000, 6:253-301

14. Meade M, Guyatt G, Sinuff T, Griffith L, Hand L, Toprani G, Cook $D$ : Trials comparing alternative weaning modes and discontinuation assessments. Chest 2001, 120:425S-437S

15. El-Khatib MF, Jamaleddine G, Khoury A, Obeid M: Effect of continuous positive airway pressure on the rapid shallow breathing index in patients following cardiac surgery. Chest 2002, 121:475-479.

16. El-Khatib MF, Zeinelddine S, Jamaleddine G: The effect of pressure support ventilation and positive end expiratory pressure on the rapid shallow breathing index. Intensive Care Med 2008, 34:505-510.

17. Sahn SA, Lakshminaraya S: Bedside criteria for discontinuation of mechanical ventilation. Chest 1973, 63:1002-1005.

18. Yang KL, Tobin MJ: A prospective study of indexes predicting the outcome of trials of weaning from mechanical ventilation. N Engl J Med 1991, 324:1445-1450.

19. Chatila W, Jacob B, Guaglionone D, Manthous CA: The unassisted respiratory rate:tidal volume ratio accurately predicts weaning outcome. Am J Med 1996, 101:61-67.

20. Jacob B, Chatila W, Manthous CA: The unassisted respiratory rate:tidal volume ratio accurately predicts weaning outcome in post-operative patients. Crit Care Med 1996, 25:253-257.

21. Martinez A, Seymour C, Nam M: Minute ventilation recovery time: a predictor of extubation outcome. Chest 2003, 123: 1214-1221.

22. Trwit JD, Marini JJ: Validation of a technique to assess maximal inspiratory pressure in poorly cooperative patients. Chest 1992, 102:1216-1219.

23. Bruton A: A pilot study to investigate any relationship between sustained maximal inspiratory pressure and extubation outcome. Heart Lung 2002, 31:141-149.

24. Holliday JE, Hyers TM: The reduction of weaning time from mechanical ventilation using tidal volume and relaxation feedback. Am Rev Respir Dis 1990, 141:1214-1220.

25. Maclntyre NR: Weaning from mechanical ventilatory support: volume-assisting intermittent breaths versus pressureassisting every breaths. Respir Care 1988, 33:121-125.

26. Engoren $\mathrm{M}$ : Approximate entropy of respiratory rate and tidal volume during weaning from mechanical ventilation. Crit Care Med 1998, 26:1817-1823.

27. El-Khatib MF, Jamaleddine G, Soubra R, Muallem M: Pattern of spontaneous breathing: potential marker for weaning outcome. Spontaneous breathing pattern and weaning from mechanical ventilation. Intensive Care Med 2001, 27:52-58.

28. DeHaven CB, Kirton OC, Morgan JP, Hart AM, Shatz DV, Civetta $\mathrm{JM}$ : Breathing measurement reduces false-negative classification of tachypneic preextubation trial failures. Crit Care Med 1996, 24:976-980.

29. Kacmarek RM: Point of view: pressure support. Respir Care 1989, 34:136-138.

30. Tobin MJ, Perez W, Guenther SM, Semmes BJ, Mador MJ, Allen SJ, Lodato RF, Dantzker DR: The pattern of breathing during successful and unsuccessful trials of weaning from mechanical ventilation. Am J Respir Dis 1986, 134:1111-1118.

31. Nava S, Zanotti E, Rubini F: Weaning and outcome from mechanical ventilation. Monaldi Arch Chest Dis 1994, 49:530532.

32. Mergoni M, Costa A, Primavera S, Salvadori A, Saccani A, Zuccoli $P$ : Assessment of various new predictive parameters of the outcome of mechanical ventilation weaning. Minerva Anesthesiol 1996, 62:153-164.

33. Vassilakopoulos T, Zakynthinos S, Roussos C: The tension-time index and the frequency/tidal volume ratio are the major pathophysiologic determinants of weaning failure and success. Am J Respir Crit Care Med 1998, 158:378-385.

34. Vassilakopoulos T, Routsi C, Sotiropoulo C, Bitsakou C, Stanopoulos I, Roussos C, Zakynthinos S: The combination of the load/force balance and the frequency/tidal volume can predict weaning outcome. Intensive Care Med 2006, 32:684691.

35. Lee KH, Hui KP, Chan TB, Tan WC, Lim TK: Rapid shallow breathing (frequency-tidal volume ratio) did not predict extubation outcome. Chest 1994, 105:540-543.

36. Epstein SK: Evaluation of the rapid shallow breathing index in the clinical setting. Am J Respir Crit Care Med 1995, 152:545549.

37. Pierson DJ: Weaning from mechanical ventilation: why all the confusion? Resp Care 1995, 40:228-233.

38. Krieger BP, Isber J, Breitenbucher A, Throop G, Ershowsky P: Serial measurements of the rapid-shallow breathing index as a predictor of weaning outcome in elderly medical patients. Chest 1997, 112:1029-1034.

39. Alvisi R, Volta CA, Righini ER, Capuzzo M, Ragazzi R, Verri M, Candini G, Gritti G, Milic-Emili J: Predictors of weaning outcome in chronic obstructive pulmonary disease patients. Eur Respir J 2000, 15:656-662.

40. Tanios M, Nevins M, Hendra K, Cardinal P, Allan J, Naumova E, Epstein S: A randomized, controlled trial of the role of weaning predictors in clinical decision making. Crit Care Med 2006, 34:2530-2535.

41. Tobin MJ: Advances in mechanical ventilation. $N$ Engl J Med 2001, 344:1986-1996.

42. Kuhlen R, Hausmann S, Pappert D, Slama K, Rossaint R, Falke K: A new method for P0.1 measurement using standard respiratory equipment. Intensive Care Med 1995, 21:554-560.

43. Capdevila XJ, Perrigault PF, Perey PJ, Roustan JP, d'Athis F: Occlusion pressure and its ratio to maximum inspiratory pressure are useful predictors for successful extubation following T-piece weaning trial. Chest 1995, 108:482-489.

44. Hess D, Kacmarek R: Weaning from mechanical ventilation. In Essentials of Mechanical Ventilation. 2nd edition. Columbus, $\mathrm{OH}$ : McGraw-Hill; 2002:121-135.

45. Jones DP, Byrne P, Morgan C, Fraser I, Hyland R: Positive endexpiratory pressure versus T-piece; extubation after mechanical ventilation. Chest 1991, 100:1655-1659.

46. Wysocki M, Cracco C, Teixeira A, Mercat A, Diehl J-L, Lefort $Y$, Derenne J-P, Similowski T: Reduced breathing variability as a predictor of unsuccessful patient separation from mechanical ventilation. Crit Care Med 2006, 34:2076-2083.

47. Perren A, Domenighetti G, Mauri S, Genini F, Vizzardi N: Protocol-directed weaning from mechanical ventilation: clinical outcome in patients randomized for a $30-\mathrm{min}$ or $120-\mathrm{min}$ trial with pressure support ventilation. Intensive Care Med 2002, 28:1058-1063.

48. Vitacca M, Vianello A, Colombo D, Clini E, Porta R, Bianchi L, Arcaro G, Vitale G, Guffanti E, Lo Coco A, Ambrosino N: Comparison of two methods for weaning patients with chronic obstructive pulmonary disease requiring mechanical ventilation for more than 15 days. Am J Respir Crit Care Med 2001, 164:225-230. 
49. Banner MJ, Kirby RR, Blanch PB, Layon AJ: Decreasing imposed work of breathing apparatus to zero using pressuresupport ventilation. Crit Care Med 1993, 21:1333-1338.

50. Brochard L, Rua F, Lorino H, Lemaire F, Harf A: Inspiratory pressure support compensates for the additional work of breathing caused by the endotracheal tube. Anesthesiology 1991, 75:739-745.

51. Wright $\mathrm{PE}$, Marini JJ, Bernard GR: In vitro versus in vivo comparison of endotracheal tube airflow resistance. Am Rev Respir Dis 1989, 140:10-16.

52. Ezingeard E, Diconne e, Guyomarc'h S, Venet C, Page D, Gery P, Vermsch R, Bertrand M, Pingat J, Tardy B, Bertrand JC, Zeni F: Weaning from mechanical ventilation with pressure support in patients failing a T-tube trial of spontaneous breathing. Intensive Care Med 2006, 32:165-169.

53. Imsand C, Feihl F, Perret C, Fitting JW: Regulation of inspiratory neuromuscular output during synchronized intermittent mechanical ventilation. Anesthesiology 1994, 80:13-22.

54. Marini JJ, Rodriguez RM, Lamb V: The inspiratory workload of patient-initiated mechanical ventilation. Am Rev Respir Dis 1986, 134:902-909.

55. Leung $P$, Jubran A, Tobin MJ: Comparison of assisted ventilator modes on triggering, patient effort, and dyspnea. Am J Respi Crit Care Med 1997, 155:1940-1948.

56. Kuhlen R, Max M, Dembinski R, Terbeck S, Jurgens E, Rossaint R: Breathing pattern and workload during automatic tube compensation, pressure support and T-piece trials in weaning patients. Eur J Anesthesiol 2003, 20:10-16.

57. Cohen J, Shapiro M, Grozovski E, Lev S, Fisher H, Singer P: Extubation outcome following a spontaneous breathing trial with automatic tube compensation versus continuous positive airway pressure. Crit Care Med 2006, 34:682-686.

58. Georgopoulos D: Proprtional assist ventilation: an alternative approach to wean the patient. Eur J Anaesthesiol 1998, 15: 756-760.

59. Sinderby C, Beck J: Proportional assist ventilation and neurally adjusted ventilatory assist - better approaches to patient ventilator synchrony? Clin Chest Med 2008, 29:329-342.

60. Del Rosario N, Sassoon CS, Chetty KG, Gruer SE, Mahutte CK: Breathing pattern during acute respiratory failure and recovery. Eur Respir J 1997, 10:2560-2565.

61. Kirton OC, DeHaven CB, Morgan JP, Windsor J, Civetta JM: Elevated imposed work of breathing masquerading as ventilator weaning intolerance. Chest 1995, 108:1021-1025.

62. Strauss C, Louis B, Isabey D, Lemaire F, Harf A, Brochard L: Contribution of the endotracheal tube and the upper airway to breathing workload. Am J Respir Crit Care Med 1998, 157: 23-30.

63. Manthous CA, Schmidt GA: Resistive pressure of a condenser humidifier in mechanically ventilated patients. Crit Care Med 1994, 22:1792-1795.

64. Zanotti E, Rubini F, lotti G, Braschi A, Palo A, Bruschi C, Fracchia C, Nava S: Elevated static compliance of the total respiratory system: early predictor of weaning unsuccess in several COPD patients mechanically ventilated. Intensive Care Med 1995, 21:399-405.

65. Murata K, Kubota T: Impairment of chest wall mechanics and increased chest wall work of breathing cause postoperative respiratory failure in patients who have undergone radical esophagotomy. J Anesth 2001, 15:125-131.

66. Tassaux D, Gainnier M, Battisti A, Jolliet P: Helium-oxygen decreases inspiratory effort and work of breathing during pressure support in intubated patients with chronic obstructive pulmonary disease. Intensive Care Med 2005, 31:15011507.

67. Ranieri VM, Mascia L, Petruzzelli V, Bruno F, Guiliani R: Inspiratory effort and measurement of dynamic intrinsic PEEP in COPD patients: effects of ventilator triggering systems. Intensive Care Med 1995, 21:896-903.

68. Reddy VG: Auto-PEEP: how to detect and how to prevent. Middle East J Anesthesiol 2005, 18:293-312.

69. Jubran A, Mathru M, Dries D, Tobin MJ: Continuous recordings of mixed venous oxygen saturation during weaning from mechanical ventilation and the ramifications thereof. $\mathrm{Am} J$ Respir Crit Care Med 1998, 158:1763-1769.

70. Marcellino R, Fernandes AP, Marum S, Ribeiro JP: The influence of cardiac diastole on weaning from mechanical ventilation.
Rev Port Cardiol 2002, 21:849-857.

71. Grasso S, Leone A, De Michele M, Anaclerio R, cafarelli A, Ancona G, Stripoli T, Bruno F, Pugliese P, Dambrosio M, Dalfino $\mathrm{L}$, Di Serio $\mathrm{F}$, Fiore $\mathrm{T}$ : Use of $\mathrm{N}$-terminal pro-brain natriuretic peptide to detect acute cardiac dysfunction during weaning failure in difficult-to-wean patients with chronic obstructive pulmonary disease. Crit Care Med 2007, 35:96-105.

72. Frazier SK, Brom H, Widener J, Pender L, Stone KS, Moser DK: Prevalence of myocardial ischemia during mechanical ventilation and weaning and its effects on weaning success. Heart Lung 2006, 35:363-373.

73. Srivastava S, Chatila W, Amoateng-Adjepong Y, Kanagasegar S, Jacob B, Zarich S, Manthous CA: Myocardial ischemia and weaning failure in patients with coronary artery disease: an update. Crit Care Med 1999, 27:2109-2112.

74. Vieira JM Jr, Castro I, Curvello-Neto A, Demarzo S, Caruso P, Pastore L Jr, Imanishe MH, Abdulakader RC, Deheinzelin D: Effect of acute kidney injury on weaning from mechanical ventilation in critically ill patients. Crit Care Med 2007, 35:184191.

75. Behnia M, Clay AS, Farber MO: Management of myxedematous respiratory failure: review of ventilation and weaning principles. Am J Med Sci 2000, 320:368-373.

76. Huang CJ, Lin HC: Association between adrenal insufficiency and ventilator weaning. Am J Respir Crit Care Med 2006, 173: 276-280.

77. Frutos-Vivar F, Esteban A: Critical illness polyneuropathy: a new (or old?) reason for weaning failure. Crit Care Med 2005, 33:452-453.

78. Garnacho-Montero J, Amaya-Villar R, Garcia-Garmendia J, Madrazo-Osuna J, Ortiz-Leyba C: Effect of critical illness polyneuropathy on the withdrawal from mechanical ventilation and the length of stay in septic patients. Crit Care Med 2005, 33:349-354.

79. Reid C: Frequency of under- and overfeeding in mechanically ventilated ICU patients: causes and possible consequences. $J$ Hum Nutr Diet 2006, 19:13-22.

80. Pierson DJ: Nonrespiratory aspects of weaning from mechanical ventilation. Resp Care 1995, 40:263-271.

81. Cook D, Meade M, Guyatt G, Butler R, Aldawood A, Epstein S: Trials of miscellaneous interventions to wean from mechanical ventilation. Chest 2001, 120:438S-444S.

82. Martensson IE, Fridlund $\mathrm{B}$ : Factors influencing the patient during weaning from mechanical ventilation: a national survey. Intensive Crit Care Nurs 2002, 18:219-229.

83. Thomas LA: Clinical management of stressors perceived by patients on mechanical ventilation. AACN Clin Issues 2003, 14:73-81.

84. Nelson JE, Meier DE, Litke A, Natale DA, Siegel RE, Moeeison RS: The symptom burden of chronic critical illness. Crit Care Med 2004, 32:1527-1534.

85. Girard T, Kress J, Fuchs B, Thomason J, Schweickert W, Pun B, Taichman D, Dunn J, Pohlman A, Kinniry P, Jackson J, Canonico A, Light R, Shintani A, Thompson J, Gordon S, Hall J, Dittus R, Bernard G, Ely EW: Efficacy and safety of paired sedation and ventilator weaning protocol for mechanically ventilated patients in intensive care (awakening and breathing Controlled trial): a randomized controlled trial. Lancet 2008, 371: 126-134.

86. Polese G, Massara A, Poggi R, Brandolese R, Brandi G, Rossi A: Flow-triggering reduces inspiratory effort during weaning from mechanical ventilation. Intensive Care Med 1995, 21:682686.

87. Racca F, Squadrone V, Ranieri VM: Patient-ventilator interaction during the triggering phase. Respir Care Clin N Am 2005, 11:225-245.

88. Shneerson JM: Are there new solutions to old problems with weaning. Br J Anaesth 1997, 78:238-240.

89. Ely EW: The utility of weaning protocols to expedite liberation from mechanical ventilation. Respi Care Clin N Am 2000, 6: 303-319.

90. McLean SE, Jensen LA, Schroeder DG, Gibney NR, Skjodt NM: Improving adherence to a mechanical ventilation weaning protocol for critically ill adults: outcomes after implementation program. Am J Crit Care 2006, 15:299-309.

91. Hendrix H, Kaiser ME, Yusen RD, Merk J: A randomized trial of automated versus conventional protocol-driven weaning from 
mechanical ventilation following coronary artery bypass surgery. Eur J Cardiothorac Surg 2006, 29:957-963.

92. Gutierrez CJ, Harrow J, Haines F: Using an evidence-based protocol to guide rehabilitation and weaning of ventilatordependent cervical spinal cord injury patients. J Rehabil Res Dev 2003, 40:99-110.

93. Ramachandran V, Jo Grap M, Sessler C: Protocol-directed weaning: a process of continuous performance improvement. Crit Care 2005, 9:138-140.

94. Hill NS: Following protocol: weaning difficult-to-wean patients with chronic obstructive pulmonary disease. Am J Respir Crit Care Med 2001, 164:186-187.

95. Marelich GP, Murin S, Battistella F, Inciardi J, Vierra T, Roby M: Protocol weaning of mechanical ventilation in medical and surgical patients by respiratory care practitioners and nurses: effect on weaning time and incidence of ventilator-associated pneumonia. Chest 2000, 118:459-467.

96. Dries DJ, McGonigal MD, Malian MS, Bor BJ, Sullivan C: Protocol-driven ventilator weaning reduces use of mechanical ventilation, rate of early reintubation, and ventilator-associated pneumonia. J Trauma 2004, 56:943-951.

97. Iregui $\mathrm{M}$, Ward S, Clinikscale D, Clayton D, Kollef $\mathrm{MH}$ : Use of handheld computer by respiratory care practitioners to improve the efficiency of weaning patients from mechanical ventilation. Crit Care Med 2002, 30:2038-2043.

98. Lellouche F, Mancebo J, Jolliet P, Roeseler J, Schortgen F, Dojat M, Cabello B, Bouadma L, Rodriguez P, Maggiore S, Reynaert M, Mersmann S, Brochard L: A multicenter randomized trial of computer-driven protocolized weaning from mechanical ventilation. Am J Respir Crit Care Med 2006, 174:849-851.

99. Petter $\mathrm{AH}$, Chiolro RL, Cassina T, Chassot PG, Muller XM, Revelly JP: Automatic "respiratory/weaning" with adaptive support ventilation: the effect on duration of endotracheal intubation and patient management. Anesth Analg 2003, 97: 1743-1750.

100. Duane T, Riblet J, Golay D, Cole F, Weireter L, Britt L: Protocoldriven ventilator management in trauma intensive care unit population. Arch Surg 2002, 137:1223-1227.

101. Ely EW, Baker AM, Dunagan DP, Burke HL, Smith AC, Kelly PT, Johnson MM, Browder RW, Bowton DL, Haponik EH: Effect on the duration of mechanical ventilation of identifying patients capable of breathing spontaneously. N Engl J Med 1996, 335:1864-1869.

102. Grap MJ, Strickland D, Tormey L, Keane K, Lubin S, Emerson J, Winfield S, Townes R, Sessler CN: Collaborative practice: development, implementation, and evaluation of weaning protocol for patients receiving mechanical ventilation. $A m$ J Crit Care 2003, 12:454-460.

103. Kollef MH, Shapiro SD, Silver P, St John RE, Prentice D, Sauer S, Ahrens TS, Shannon W, Baker-Clinkscale D: A randomized, controlled trial of protocol-directed versus physician-directed weaning from mechanical ventilation. Crit Care Med 1997, 25: 567-574.

104. Blackwood B, Wilson-Barnett J, Trinder J: Protocolized weaning from mechanical ventilation: ICU physicians' views. J Adv Nurs 2004, 48:26-34.

105. Blackwood B, Wilson-Barnett J, Patterson CC, Trinder TJ, Lavery GG: An evaluation of protocolised weaning on the duration of mechanical ventilation. Anaesthesia 2006, 61:1079-1086.

106. Tonnelier JM, Prat G, Le Gal G, Gut-Gobert C, Renault A, Boles $J M$, L'Her E: Impact of a nurses' protocol-directed weaning procedure on outcomes in patients undergoing mechanical ventilation for longer than $\mathbf{4 8}$ hours: a prospective cohort study with a matched historical control group. Crit Care 2005, 9:R83-R89.

107. Goodman S: Implementing a protocol for weaning patients off mechanical ventilation. Nurs Crit Care 2006, 11:23-32

108. Ferrer M, Esquinas A, Aranciba F, Thomas -Bauer T, Gonzalez G, Carrillo A, Rodriguez-Roisin R, Torres A: Noninvasive ventilation during persistent weaning failure. Am J Respir Crit Care Med 2003, 168:70-76.

109. Nava S, Ambrossino N, Clini E, Prato M, Orlando G, Vitacca M, Brigada $P$, Fracchia C, Rubini F: Noninvasive mechanical ventilation in the weaning of patients with respiration failure due to chronic obstructive pulmonary disease: a randomized, controlled trial. Ann Intern Med 1998, 128:721-728.

110. Burns KE, Adhikari NK, Meade MO: A meta-analysis of noninva- sive weaning to facilitate liberation from mechanical ventilation. Can J Anaesth 2006, 53:305-315.

111. Esteban A, Frutos-Vivar F, Ferguson N, Arabi $Y$, Apezteguia $C$ Gonzales M, Epstein S, Hill N, Nava S, Soares M-A, D'Empaire G, Alia I, Anzueto A: Noninvasive positive-pressure ventilation for respiratory failure after extubation. N Engl J Med 2004, 350: 2452-2460.

112. Esteban A, Alia I, Gordo F, Fernandez R, Solsona J, Vallverdu I, Macias S, Allegue J, Blanco J, carriedo D, Leon M, de La Cal M, Taboada F, Gonzalea de Velasco J, Palazon E, Carrizosa F, Tomas R, Suarez J, Goldwasser R: Extubation outcome after spontaneous breathing trials with T-piece or pressure support ventilation: the Spanish Lung Failure Collaborative Group. Am J Respir Crit Care Med 1997, 156:459-465.

113. Esteban A, Alia I, Tobin M, Gil A, Gordo F, Vallverdu I, Blanch L, Bonet A, Vazquez A, de Pablo R, Torres A, de La Cal M, Macias $\mathrm{S}$ : Effect of spontaneous breathing trial duration on outcome of attempts to discontinue mechanical ventilation: Spanish Lung Failure Collaborative Group. Am J Respir Crit Care Med 1999, 159:512-518.

114. Khamiees M, Raju P, DeGirolamo A, Amoateng-Adjepong Y, Manthous C: Predictors of extubation outcome in patients who have successfully completed a spontaneous breathing trial. Chest 2001, 120:1262-1270.

115. Salam A, Tilluckdharry L, Amoateng-Adjepong Y, Manthous C: Neurologic status, cough, secretions and extubation outcomes. Intensive Care Med 2004, 30:1334-1339.

116. Francois B, Bellissant E, Gissot V, Desachy A, Sandrine N, Boulain T, Brenet O, Preux P-M, Vignon P: 12-h pretreatment with methylprednisolone versus placebo for prevention of postextubation laryngeal oedema: a randomized double-blind trial. Lancet 2007, 369:1083-1089.

117. Pierson DJ: Tracheostomy and weaning. Respir Care 2005, 50: 526-533.

118. Hsu CL, Chen KY, Chang CH, Jerng JS, Yu CJ, Yang PC: Timing of tracheostomy as a determinant of weaning success in critically ill patients: a retrospective study. Crit Care 2005, 9:R46R52.

119. Boynton JH, Hawkins K, Eastridge BJ, O'Keefe GE: Tracheostomy timing and the duration of weaning in patients with acute respiratory failure. Crit Care 2004, 8:R261-R267.

120. Diehl JL, El Atrous S, Trouchard D, Lemaire F, Brochard L: Changes in the work of breathing induced by tracheostomy in ventilator-dependent patients. Am J Respir Crit Care Med 1999, 159:383-388.

121. Davis K Jr, Campbell RS, Johannigman JA, Valente JF, Branson $\mathrm{RD}$ : Changes in respiratory mechanics after tracheostomy. Arch Surg 1999, 134:59-62.

122. Grinnan D, Truwit J: Clinical review: respiratory mechanics in spontaneous and assisted ventilation. Crit Care 2005, 9:472. 484. 